\title{
Association between maternal vitamin D status in pregnancy and neurodevelopmental outcomes in childhood: results from the Avon Longitudinal Study of Parents and Children (ALSPAC)
}

\author{
Andrea L. Darling ${ }^{1}$, Margaret P. Rayman ${ }^{1}$, Colin D. Steer ${ }^{2}$, Jean Golding ${ }^{2}$, Susan A. Lanham-New ${ }^{1}$ \\ and Sarah C. Bath ${ }^{1 *}$ \\ ${ }^{1}$ Department of Nutritional Sciences, School of Biosciences and Medicine, Faculty of Health and Medical Sciences, \\ University of Surrey, Guildford GU2 $7 X H$, UK \\ ${ }^{2}$ School of Social and Community Medicine, Centre for Child and Adolescent Health, University of Bristol, Bristol BS8 2BN, UK \\ (Submitted 27 September 2016 - Final revision received 7 April 2017 - Accepted 15 May 2017 - First published online 12 July 2017)
}

\section{Abstract}

Seafood intake in pregnancy has been positively associated with childhood cognitive outcomes which could potentially relate to the high vitamin D content of oily fish. However, whether higher maternal vitamin D status (serum 25-hydroxyvitamin D (25(OH)D)) in pregnancy is associated with a reduced risk of offspring suboptimal neurodevelopmental outcomes is unclear. A total of 7065 mother-child pairs were studied from the Avon Longitudinal Study of Parents and Children cohort who had data for both serum total 25(OH)D concentration in pregnancy and at least one measure of offspring neurodevelopment (pre-school development at 6-42 months; 'Strengths and Difficulties Questionnaire' scores at 7 years; intelligence quotient (IQ) at 8 years; reading ability at 9 years). After adjustment for confounders, children of vitamin D-deficient mothers $(<50.0 \mathrm{nmol} / \mathrm{l})$ were more likely to have scores in the lowest quartile for gross-motor development at 30 months (OR 1.20; $95 \%$ CI 1.03, 1.40), fine-motor development at 30 months (OR 1.23; $95 \%$ CI 1.05, 1.44) and social development at 42 months (OR 1.20; $95 \%$ CI $1.01,1.41)$ than vitamin D-sufficient mothers $(\geq 50.0 \mathrm{nmol} / \mathrm{l})$. No associations were found with neurodevelopmental outcomes, including IQ, measured at older ages. However, our results suggest that deficient maternal vitamin D status in pregnancy may have adverse effects on some measures of motor and social development in children under 4 years. Prevention of vitamin D deficiency may be important for preventing suboptimal development in the first 4 years of life.

Key words: Prenatal vitamin D: 25-Hydroxyvitamin D: Motor development: Social development: Intelligence quotient and reading ability: Avon Longitudinal Study of Parents and Children

The consumption of fish, or nutrients present in fish, by pregnant women has been linked to neurocognitive development in their children. In observational studies, maternal intake of fish or seafood in pregnancy has been positively associated with cognitive scores in the offspring ${ }^{(1-4)}$, whereas children whose mothers had eaten oily fish in early pregnancy had a reduced risk of hyperactivity than those whose mothers did not eat oily fish $^{(3)}$. Although these studies tended to interpret these associations as effects of long-chain $n$ - 3 fatty acids, they might also be explained by the fact that oily fish is the best dietary source of vitamin D. Though the action of sunlight on the skin is the predominant contributor to vitamin D status, dietary vitamin D can play an important role in determining status, as measured by the vitamin D metabolite, 25-hydroxyvitamin D (25(OH)D), in serum or plasma ${ }^{(5)}$. Dietary sources of vitamin D (especially oily fish) are particularly important during the winter months when endogenous production of vitamin D status is limited.
It is biologically plausible that vitamin D status in pregnant mothers may affect child neurocognitive development as vitamin $\mathrm{D}$ receptors are present in the brain $^{(6)}$ and maternal vitamin $\mathrm{D}$ deficiency is known to be associated with abnormal brain development in the young rat $^{(7)}$. In the period from birth to weaning in rats, there appears to be a window during which maternal vitamin D status affects offspring brain development ${ }^{(8)}$ and these developmental changes may not occur if vitamin D is withheld until weaning ${ }^{(9)}$. Furthermore, vitamin D deficiency in late gestation can lead to impaired brain function in adult rats ${ }^{(8)}$. Due to differences between rat and human developmental physiology, the extent to which these findings would apply to humans remains unclear.

Few human studies have assessed the relationship between maternal vitamin D status and neurodevelopmental outcomes. The results of the five published observational studies that exist are inconsistent ${ }^{(10-14)}$. Indeed, this fact was recently highlighted

Abbreviations: 25(OH)D, serum 25-hydroxyvitamin D; ALSPAC, Avon Longitudinal Study of Parents and Children; IQ, intelligence quotient.

* Corresponding author: Dr S. C. Bath, email s.bath@surrey.ac.uk 
in the report from Public Health England on Vitamin D and Health from the Scientific Advisory Committee for Nutrition ${ }^{(15)}$.

To address this lack of consistent evidence with respect to the association between maternal vitamin $\mathrm{D}$ status and cognitivedevelopmental outcomes in the offspring, we analysed data from the Avon Longitudinal Study of Parents and Children (ALSPAC) cohort. Our a priori hypothesis was that poorer maternal vitamin D status, as measured by serum 25(OH)D, would be associated with increased probability of suboptimal cognitive or behavioural development scores in children aged 6 months to 9 years.

\section{Methods \\ Study design and participants}

Details of ALSPAC methods have been detailed previously ${ }^{(16)}$. In brief, all pregnant women living in the former Avon area in southwest England, who had an expected delivery date between 1 April 1991 and 31 December 1992 were eligible for inclusion. A total of 14541 women were recruited, and there were 13617 mother-child pairs with singleton offspring alive at one year. The ALSPAC study website contains details of all the data that are available through a fully searchable data dictionary (http://www.bris.ac.uk/alspac/). Our study sample consisted of mother-child pairs that had both a serum 25(OH)D measure in pregnancy and at least one neurodevelopmental outcome of interest from 6 months to 9 years (Fig. 1). A range of outcomes was explored, including motor development, communication and social skills, behaviour, cognition and reading ability.

\section{Outcomes}

The ALSPAC pre-school development tests, which were based on questionnaires completed by the mother when the child was between 6 and 42 months of age, provided scores for four domains: fine motor, gross motor, social development and communication (details published previously ${ }^{(1)}$ ). The Strengths and Difficulties Questionnaire (SDQ) ${ }^{(17)}$ was completed by mothers when the child was 81 months of age and was used to assess behavioural development. Intelligence quotient (IQ) at age 8 years had been assessed in the ALSPAC clinic using the abbreviated form of the Wechsler Intelligence Scale for Children, as previously described ${ }^{(1)}$. Reading ability (accuracy, comprehension and speed) was assessed at age 9 years by trained psychologists using the Neale Analysis of Reading Ability $^{(18)}$ and by asking children to read real words to derive a reading score. Further details of these outcomes are available in the online Supplementary Material.

\section{Maternal vitamin D status}

Although 25(OH)D has lower biological activity than the active vitamin $\mathrm{D}$ hormone, 1,25-dihydroxyvitamin $\mathrm{D}\left(1,25(\mathrm{OH})_{2} \mathrm{D}\right)$, serum/plasma $25(\mathrm{OH}) \mathrm{D}$ is widely regarded as the most reliable marker of vitamin D status ${ }^{(19)}$. Total maternal serum $25(\mathrm{OH}) \mathrm{D}$ concentration (including both vitamin $\mathrm{D}_{2}$ and vitamin $\mathrm{D}_{3}$ ) in ALSPAC mothers had been measured in a previous study by
HPLC and tandem MS, in accordance with Vitamin D External Quality Assessment Scheme requirements; full details have been published previously ${ }^{(20)}$, including details of inter-assay $\mathrm{CV}^{(21)}$.

\section{Statistical analysis}

The women with vitamin D measurements were compared with the remaining ALSPAC women. We compared categorical variables with $\chi^{2}$ tests and continuous variables with independent $t$ tests. We used median and inter-quartile range (IQR) to describe maternal vitamin $\mathrm{D}$ status. Our main analysis dichotomised women as deficient or sufficient using $25(\mathrm{OH}) \mathrm{D}$ concentration $\leq 50.0 \mathrm{nmol} / 1$ as the cut-off for vitamin D deficiency, as in previous ALSPAC work ${ }^{(20)}$. We did additional supplementary analyses by dividing women into three categories $(<25 \cdot 0,25 \cdot 0-49.9$ and $\geq 50 \cdot 0 \mathrm{nmol} / \mathrm{l})$ to explore the dose-response relationship.

We used logistic regression to examine the relationship between maternal vitamin D status in pregnancy and odds of suboptimal development with the women in the vitamin D-sufficient group ( $>50.0 \mathrm{nmol} / \mathrm{l})$ as the reference category. We did not input missing confounder or outcome data with replacement values. We defined suboptimal development as scores in the lowest quartile for all subscales of early development, IQ and reading ability, as in previous ALSPAC research ${ }^{(1,22)}$. For the SDQ, suboptimal behaviour was defined according to published cut-offs (for both the individual scales and overall score) that indicate borderline/abnormal behaviour ${ }^{(17)}$ (see the Supplementary Material, Study Outcomes). Model predictors were assessed for potential multicollinearity. For our final model, variance inflation factor ranged from 1.02 to $2 \cdot 2$ (accordingly tolerance ranged from 0.5-0.99) depending on the variable.

As vitamin D status and childhood cognitive and behavioural development are affected by a range of factors ${ }^{(23,24)}$, we included potential confounders in our analysis. The confounders chosen were based on previous ALSPAC findings ${ }^{(1,22)}$ and were from questionnaire and clinic-based data (Table 1). We included ten categorical and two continuous variables. The two continuous variables were maternal age (years), and maternal BMI $\left(\mathrm{kg} / \mathrm{m}^{2}\right)$. As there is a well-established relationship between BMI and $25(\mathrm{OH}) \mathrm{D}$ concentration ${ }^{(25)}$, maternal BMI was included in the model, even though it was not statistically associated with $25(\mathrm{OH}) \mathrm{D}$ in this data set (Table 1$)$.

The ten categorical variables comprised three groups: (i) child factors (sex and breast-feeding (none or some)), (ii) maternal factors (ethnicity (white or non-white), tobacco use in the first trimester (smoker or non-smoker), parity (zero, one or more) and oily-fish intake in pregnancy (never/rarely or once a fortnight or more)) and (iii) markers of socio-economic development (maternal education (low = less than O-level or equivalent; medium $=\mathrm{O}$-level and high $=$ greater than $\mathrm{O}-$ level $)$, home ownership (mortgaged/owned, privately rented or housing association/council rented/other), maternal social class based on her occupation (non-manual and manual) and crowding in the home (less than or equal to one person or greater than one person per room)). We also included two variables to control for variation in the vitamin D 


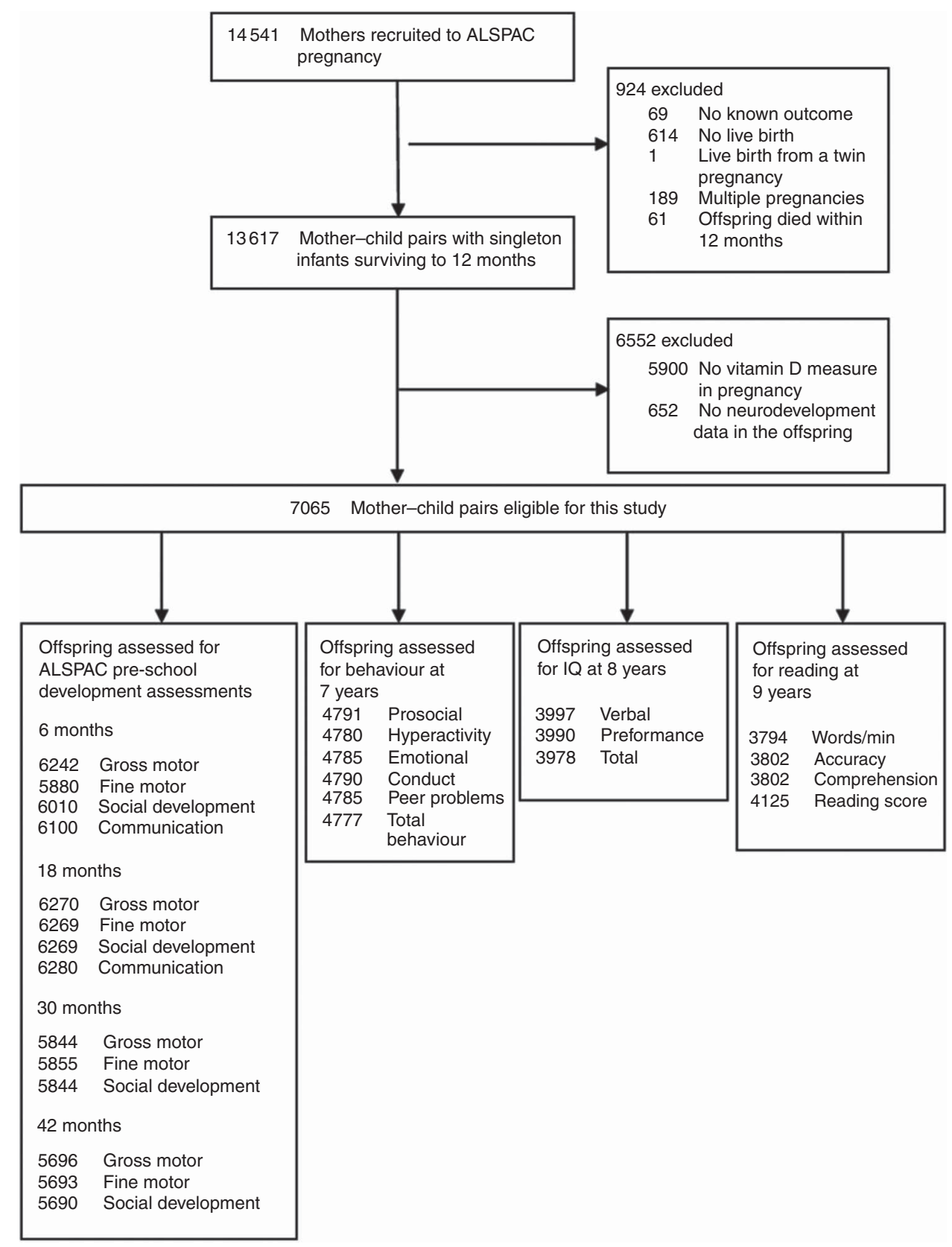

Fig. 1. Flow of participants. ALSPAC, Avon Longitudinal Study of Parents and Children; IQ, intelligence quotient.

measurement: gestation (week) and season of sample collection (spring (March, April and May), summer (June, July and August) autumn (September, October and November) and winter (December, January and February)). Although it is unlikely that the age of the child at assessment would be confounded by maternal vitamin D status, outcomes were adjusted for child age at the 6-month measurement, owing to the strong association between age and outcomes at this early life stage.

We used three models to adjust the analysis for potential confounders. As 25(OH)D measurements spanned pregnancy, and as gestational week is associated with vitamin D status ${ }^{(26)}$, we do not present unadjusted data; our minimally adjusted model (model 1) included gestational week of 25(OH)D measurement. Model 2 built on model 1 by including nine confounders associated with both vitamin D status (Table 1) and cognitive development (parity, tobacco smoking, housing status, crowding, maternal age, BMI, education, ethnic group and social class) and two child factors (sex and breast-feeding). Model 3 included model 2 confounders plus two variables (oily fish intake and season of vitamin D measurement) that could affect maternal vitamin $\mathrm{D}$ status though including these may represent an over-control.

We used simulations to assess the impact of multiple comparisons. We generated 5000 data sets where $25(\mathrm{OH}) \mathrm{D}$ measurements were randomly permutated across valid observations with these data. As a consequence, all analyses 
maintained the same number of observations and, with all other data unchanged, the correlations between outcomes and confounders were preserved. The analyses were based upon model 3. The effect of randomisation was to generate a set of results under the null hypothesis to which our set of observed results could be compared. A composite score across the twenty-seven outcomes was based upon the sum of $P$ values. These were modified to one-sided tests to allow results in the same direction to contribute consistently to the score, whether statistically significant or not. $P$ values in the tables are not corrected for multiple comparisons.

\section{Sensitivity analysis}

We conducted analyses with two additional confounders (added to model 3) that might be on the causal pathway: preterm birth $(<37$ or $\geq 37$ weeks $)$ and birth weight $(<2500$ or $\geq 2500 \mathrm{~g}$ ). We also explored the effect of including maternal iodine status in the first trimester (sufficient $(\geq 150 \mu \mathrm{g} / \mathrm{g}$ ) or deficient $(<150 \mu \mathrm{g} / \mathrm{g}))$ as we have previously shown that this is associated with child cognition in the ALSPAC cohort ${ }^{(22)}$. As just 787 women also had a measure of iodine status in the first trimester, we used a simplified model (total of thirteen confounders) to ensure that the model would converge (we dropped ethnicity and crowding in the home as a result of low numbers in the categories of those variables).

As there is ongoing controversy in the published literature with respect to the definition of vitamin $\mathrm{D}$ deficiency ${ }^{(27)}$, we conducted sensitivity analyses using a wide range of vitamin D status, namely $<25.0$ and $<75.0 \mathrm{nmol} / 1$ as cut-offs (online Supplementary Tables S3 and S4). Assumptions concerning statistical significance were based on interpretation of CI, rather than $P$ values, wherever possible, and multiple testing was assessed as described above. Analyses were conducted using the Statistical Package for Social Sciences (version 21.0; SPSS, Inc.).

\section{Ethics}

The ALSPAC study was conducted according to the guidelines laid down in the Declaration of Helsinki. All procedures involving human subjects were approved by the ALSPAC Ethics and Law Committee and the Local Research Ethics Committees. Written informed consent was obtained from participants (or from their parent/guardian if under 18 years old).

\section{Role of the funding source}

The funding bodies did not have a role in the study design, data collection, data analysis, data interpretation or writing of the report. The corresponding author had full access to all the study data used and final responsibility to submit for publication.

\section{Results}

Compared with the remainder of the ALSPAC cohort (defined as mother-singleton child pairs from the core sample surviving to one year), the mother-child pairs in this study were more likely to be older, of white ethnicity, with markers of higher socio-economic status (e.g. a higher proportion of breastfeeding mothers, higher educational attainment and social class and a lower proportion of smokers (online Supplementary Table S1)). However, some of the actual differences were small (e.g. maternal age 28.3 ( $\mathrm{sD} 4.8$ ) v. 27.7 (sD 4.7) years). The median 25(OH)D concentration for all 7065 women with a child that had at least one relevant outcome was 61.3 (IQR 42.9-84.7) nmol/l, with 4.4\% having <25.0 nmol/1, 34.6\% having $<50.0 \mathrm{nmol} / 1$ and $65.7 \%$ having $<75.0 \mathrm{nmol} / 1$.

The median gestational week of vitamin D measurement (available for 7064 women) was $29 \cdot 6$ (IQR 12.7-33.3) weeks, with $26 \cdot 1 \%$ in the first trimester ( $\leq 13$ weeks), $11.8 \%$ in the second trimester (IQR 14-27) weeks and $62 \cdot 1 \%$ in the third trimester ( $\geq 28$ weeks). The median $25(\mathrm{OH}) \mathrm{D}$ measurement was $54.9(\mathrm{IQR} 40 \cdot 1-72.5) \mathrm{nmol} / \mathrm{l}$ in the first trimester, 59.3 (IQR $38 \cdot 6-84 \cdot 2) \mathrm{nmol} / \mathrm{l}$ in the second trimester and 65.3 (IQR 45.2-90.4) nmol/l in the third trimester. Table 1 shows the confounders associated with maternal vitamin D status using the $50 \mathrm{nmol} / \mathrm{l}$ cut-off. Women with $25(\mathrm{OH}) \mathrm{D}$ concentration $\geq 50.0 \mathrm{nmol} / 1$ were more likely to be white, older, and have markers of higher socio-economic status (e.g. education, home ownership and reduced smoking and crowding).

Results of logistic regression models using the cut-off value for serum $25(\mathrm{OH}) \mathrm{D}$ of $<50.0 \mathrm{nmol} / 1$ to define deficiency are shown in Table 2 . In the minimally adjusted analysis (model 1), the only outcomes associated with vitamin D status were verbal IQ at 8 years and words read per minute at 9 years of age (Table 2). However, after adjustment for potential confounders, the effect on IQ and reading was attenuated and the only outcomes that remained statistically significant were gross- and fine-motor development at 30 months and social development at 42 months. With further adjustment for oily-fish intake and season (model 3), the association between maternal vitamin D status and gross-motor development also became significant at 18 months, whereas remaining associated with gross-motor and fine-motor development at 30 months and social development at 42 months (Table 2). Children born to mothers with 25(OH)D $\leq 50.0 \mathrm{nmol} / 1$ were more likely to have scores in the bottom quartile for these variables.

For the ALSPAC pre-school development assessments, when the serum $25(\mathrm{OH}) \mathrm{D}$ of $<50.0 \mathrm{nmol} / \mathrm{l}$ group was divided into $<25.0$ and $25.0-49.9 \mathrm{nmol} / \mathrm{l}$, there was evidence of a statistically significant trend to decreasing risk of suboptimal development with higher maternal $25(\mathrm{OH}) \mathrm{D}$ concentration for gross-motor skills at $18(P=0.02)$ and 30 months $(P=0.008)$, fine-motor skills at 30 months $(P=0 \cdot 01)$ and social development at 42 months $(P=0 \cdot 02)$, after adjustment for all twelve confounders in model 3 (Table 3). The effect sizes were larger for odds of suboptimal development in children of mothers in the serum $25(\mathrm{OH}) \mathrm{D}$ $<25.0 \mathrm{nmol} / 1$ group, than for the serum 25(OH)D of $25 \cdot 0-49.9 \mathrm{nmol} / 1$ group (with the $\geq 50.0 \mathrm{nmol} / 1$ group as the comparison group) for all outcomes except fine-motor development at 18 months and social development at 30 months.

The interaction between gestational week of 25(OH)D measurement and the vitamin $\mathrm{D}$ variable (i.e. deficient $v$. sufficient status) was significant for only two of twenty-seven outcomes: fine-motor skills at 30 months and performance IQ (Table 4). However, when the analysis was restricted to the ALSPAC 
Table 1. Relationship between confounders and maternal vitamin D status (Mean values and standard deviations; percentages and numbers)

\begin{tabular}{|c|c|c|c|c|c|c|c|}
\hline \multirow[b]{3}{*}{ Confounders } & \multicolumn{7}{|c|}{ Maternal vitamin D status } \\
\hline & \multicolumn{3}{|c|}{$<50.0 \mathrm{nmol} / \mathrm{l}$} & \multicolumn{3}{|c|}{$\geq 50.0 \mathrm{nmol} / \mathrm{l}$} & \multirow[b]{2}{*}{$P^{*}$} \\
\hline & Mean & SD & $n$ & Mean & SD & $n$ & \\
\hline Age of mother (years) & $27 \cdot 7$ & $4 \cdot 8$ & 2443 & $28 \cdot 6$ & 4.7 & 4622 & $<0.0001$ \\
\hline BMl of mother $\left(\mathrm{kg} / \mathrm{m}^{2}\right)$ & 23.0 & $4 \cdot 0$ & 2126 & $22 \cdot 9$ & 3.6 & 4095 & 0.43 \\
\hline \multirow{2}{*}{$\begin{array}{l}\text { Gestation of vitamin D measure } \\
\text { (weeks) }\end{array}$} & $23 \cdot 4$ & $10 \cdot 9$ & 2771 & $25 \cdot 7$ & $10 \cdot 3$ & 5174 & $<0.0001$ \\
\hline & $\%$ & $n$ & & $\%$ & $n$ & & $P+$ \\
\hline \multicolumn{8}{|l|}{ Breast-feeding } \\
\hline Some & 33.0 & 1738 & & $67 \cdot 0$ & 3526 & & $<0.0001$ \\
\hline None & $38 \cdot 8$ & 553 & & $61 \cdot 2$ & 874 & & \\
\hline \multicolumn{8}{|l|}{ Crowding in the home } \\
\hline <one person per room & 33.9 & 2140 & & $66 \cdot 1$ & 4170 & & $<0.0001$ \\
\hline One or more per room & $43 \cdot 6$ & 176 & & $56 \cdot 4$ & 228 & & \\
\hline \multicolumn{8}{|l|}{ Education of mother } \\
\hline Low & 37.5 & 716 & & $62 \cdot 5$ & 1195 & & $<0.0001$ \\
\hline Medium & 33.4 & 792 & & $66 \cdot 6$ & 1577 & & \\
\hline High & 31.5 & 755 & & 68.5 & 1643 & & \\
\hline \multicolumn{8}{|l|}{ Ethnicity of mother } \\
\hline White & $33 \cdot 3$ & 2171 & & $66 \cdot 7$ & 4344 & & $<0.0001$ \\
\hline Non-white & $60 \cdot 6$ & 83 & & 39.4 & 54 & & \\
\hline \multicolumn{8}{|l|}{ Sex of child } \\
\hline Male & $34 \cdot 3$ & 1266 & & $65 \cdot 7$ & 2421 & & 0.67 \\
\hline Female & $34 \cdot 8$ & 1177 & & $65 \cdot 2$ & 2201 & & \\
\hline \multicolumn{8}{|l|}{ Housing status } \\
\hline Owned/mortgaged & $32 \cdot 8$ & 1705 & & $67 \cdot 2$ & 3487 & & $<0.0001$ \\
\hline Other rented & $36 \cdot 6$ & 150 & & 63.4 & 260 & & \\
\hline Council rented & 41.0 & 491 & & $59 \cdot 0$ & 708 & & \\
\hline \multicolumn{8}{|c|}{ lodine:creatinine ratio in first trimester } \\
\hline$<150 \mu \mathrm{g} / \mathrm{g}$ (deficient) & 33.5 & 186 & & $66 \cdot 5$ & 374 & & 0.94 \\
\hline$\geq 150 \mu \mathrm{g} / \mathrm{g}$ (sufficient) & 33.2 & 76 & & $66 \cdot 8$ & 151 & & \\
\hline \multicolumn{8}{|l|}{ Oily-fish intake in pregnancy (/week) } \\
\hline Never/rarely & $37 \cdot 7$ & 1038 & & $62 \cdot 3$ & 1718 & & $<0.0001$ \\
\hline Once per fortnight or more & 31.3 & 1191 & & $68 \cdot 7$ & 2617 & & \\
\hline \multicolumn{8}{|l|}{ Parity } \\
\hline Zero & $37 \cdot 0$ & 1125 & & 63.0 & 1914 & & $<0.0001$ \\
\hline One or more & 31.9 & 1179 & & $68 \cdot 1$ & 2516 & & \\
\hline \multicolumn{8}{|l|}{ Season of vitamin D measure } \\
\hline Spring & $48 \cdot 8$ & 980 & & $51 \cdot 2$ & 1027 & & $<0.0001$ \\
\hline Summer & $15 \cdot 2$ & 268 & & $84 \cdot 8$ & 1491 & & \\
\hline Autumn & $22 \cdot 4$ & 363 & & 77.6 & 1257 & & \\
\hline Winter & 49.5 & 831 & & $50 \cdot 5$ & 847 & & \\
\hline \multicolumn{8}{|l|}{ Smoking in first trimester } \\
\hline No tobacco & $31 \cdot 7$ & 1652 & & $68 \cdot 3$ & 3567 & & $<0.0001$ \\
\hline Smoked tobacco & 42.5 & 689 & & 57.5 & 932 & & \\
\hline \multicolumn{8}{|l|}{ Social class of mother } \\
\hline Manual & $36 \cdot 6$ & 383 & & 63.4 & 664 & & 0.01 \\
\hline Non-manual & 32.5 & 1447 & & $67 \cdot 5$ & 3008 & & \\
\hline
\end{tabular}

pre-school development assessments and was split into early ( $\leq 22$ weeks) and late gestation ( $>22$ weeks), the results suggested that the effect of deficient $v$. sufficient vitamin $\mathrm{D}$ status on the majority of tests was greater in the second half of gestation. The effect sizes were generally larger in the second half of gestation and results were significant (Table 4) for gross-motor development at 18 months (OR 0.97; 95\% CI 0.76, 1.23v. OR $1.31 ; 95 \% 1 \cdot 08,1.58)$ and 30 months (OR 1.07; $95 \%$ CI 0.84,1.38 $v$. OR $1.28 ; 95 \%$ CI 1.05, 1.57), fine-motor development at 30 months (0.99; 95\% CI $0.76,1.29 v$. OR $1.37 ; 95 \%$ CI $1.12,1.67)$ and social development at 42 months (OR 1.07; $95 \%$ CI 0.82, 1.41 $v$. OR 1.28; $95 \%$ CI $1.03,1.58)$. There were no significant associations in either half of gestation for other neurodevelopmental outcomes, including the SDQ, IQ or reading ability (Table 4).

\section{Multiple comparisons}

Although only four results in Table 2 were nominally significant at the $5 \%$ level, it was noted that twenty-five of the twentyseven results in model 3 showed a detrimental effect for low vitamin $D$ status. Such a result would be highly significant $(P<0.0001)$ if the outcomes were independent. In practice, 
Table 2. Suboptimal outcomes according to maternal vitamin $D$ status $(<50.0 \mathrm{~V} . \geq 50.0 \mathrm{nmol} / \mathrm{l})$, minimally and fully adjusted for potential confounders ${ }^{\star}$ (Odds ratios and $95 \%$ confidence intervals)

\begin{tabular}{|c|c|c|c|c|c|c|c|c|c|c|c|c|c|}
\hline & \multirow[b]{2}{*}{ Age } & \multicolumn{4}{|c|}{ Model 1† } & \multicolumn{4}{|c|}{ Model $2 \ddagger$} & \multicolumn{4}{|c|}{ Model $3 \S$} \\
\hline & & OR & $95 \% \mathrm{Cl}$ & $P$ & $n$ & OR & $95 \% \mathrm{Cl}$ & $P$ & $n$ & OR & $95 \% \mathrm{Cl}$ & $P$ & $n$ \\
\hline \multicolumn{14}{|c|}{ ALSPAC pre-school development assessments } \\
\hline \multirow[t]{4}{*}{ Gross-motor skills } & 6 months॥ & 0.96 & $0.84,1.09$ & 0.49 & 6242 & 1.01 & $0.86,1 \cdot 18$ & 0.92 & 4383 & 0.96 & $0.81,1.13$ & 0.59 & 4380 \\
\hline & 18 months & 0.98 & $0.87,1.10$ & 0.74 & 6269 & $1 \cdot 10$ & $0.96,1.27$ & 0.18 & 4385 & 1.17 & $1.01,1.36$ & 0.04 & 4383 \\
\hline & 30 months & 1.02 & $0.91,1.16$ & 0.71 & 5843 & $1 \cdot 16$ & $1.00,1.34$ & 0.05 & 4135 & 1.20 & $1.03,1.40$ & 0.02 & 4133 \\
\hline & 42 months & 0.99 & $0.87,1.13$ & 0.89 & 5695 & 1.04 & $0.89,1.22$ & 0.60 & 4073 & 1.09 & $0.92,1.28$ & 0.31 & 4070 \\
\hline \multirow[t]{4}{*}{ Fine-motor skills } & 6 months\| & 0.93 & $0.82,1.05$ & 0.24 & 5880 & 1.07 & $0.92,1.25$ & 0.39 & 4141 & 1.06 & $0.91,1.25$ & 0.47 & 4139 \\
\hline & 18 months & 1.07 & $0.96,1.21$ & 0.24 & 6268 & 1.03 & $0.90,1.19$ & 0.65 & 4383 & 1.09 & $0.94,1.27$ & 0.26 & 4381 \\
\hline & 30 months & 1.09 & $0.96,1.23$ & 0.18 & 5854 & $1 \cdot 20$ & $1.04,1.40$ & 0.02 & 4138 & 1.23 & $1.05,1.44$ & 0.01 & 4136 \\
\hline & 42 months & 1.04 & $0.92,1.19$ & 0.51 & 5692 & $1 \cdot 11$ & $0.95,1.31$ & 0.19 & 4071 & 1.16 & $0.98,1.37$ & 0.08 & 4068 \\
\hline \multirow[t]{4}{*}{ Social development } & 6 months\| & 0.96 & $0.84,1.09$ & 0.52 & 6010 & 1.02 & $0.87,1.19$ & 0.81 & 4209 & 1.00 & $0.85,1.18$ & 0.98 & 4207 \\
\hline & 18 months & 1.01 & $0.89,1.15$ & 0.86 & 6268 & $1 \cdot 10$ & $0.94,1.28$ & 0.22 & 4383 & 1.14 & $0.97,1.34$ & 0.11 & 4381 \\
\hline & 30 months & 0.97 & $0.86,1.10$ & 0.64 & 5843 & 1.11 & $0.95,1.30$ & 0.18 & 4129 & 1.07 & $0.91,1.27$ & 0.42 & 4127 \\
\hline & 42 months & 1.04 & $0.92,1.18$ & 0.54 & 5689 & 1.19 & $1.02,1.39$ & 0.03 & 4069 & 1.20 & $1.01,1.41$ & 0.04 & 4066 \\
\hline \multirow[t]{2}{*}{ Communication } & 6 months\| & 0.99 & $0.85,1.15$ & 0.90 & 6100 & 0.99 & $0.83,1.20$ & 0.95 & 4285 & 0.99 & $0.81,1.20$ & 0.90 & 4283 \\
\hline & 18 months & 0.99 & $0.87,1.12$ & 0.85 & 6279 & $1 \cdot 11$ & $0.96,1.29$ & 0.17 & 4390 & 1.12 & $0.95,1.31$ & 0.18 & 4388 \\
\hline \multicolumn{14}{|l|}{ Behaviour } \\
\hline Prosocial & 7 years & 0.92 & $0.75,1.13$ & 0.40 & 4791 & 0.97 & $0.75,1.24$ & 0.78 & 3513 & 1.00 & $0.77,1.31$ & 0.98 & 3511 \\
\hline Peer problems & 7 years & 1.05 & $0.88,1.25$ & 0.58 & 4785 & 1.03 & $0.83,1.27$ & 0.80 & 3510 & 1.05 & $0.83,1.31$ & 0.70 & 3508 \\
\hline Hyperactivity & 7 years & 1.06 & $0.91,1.24$ & 0.47 & 4780 & 1.04 & $0.86,1.26$ & 0.68 & 3513 & 1.04 & $0.85,1.26$ & 0.74 & 3511 \\
\hline Emotional & 7 years & 1.17 & $0.98,1.41$ & 0.09 & 4785 & 1.14 & $0.92,1.42$ & 0.23 & 3511 & 1.20 & $0.95,1.51$ & 0.12 & 3509 \\
\hline Conduct & 7 years & $1 \cdot 13$ & $0.99,1.30$ & 0.08 & 4790 & 1.05 & $0.88,1.24$ & 0.60 & 3514 & 1.06 & $0.89,1.27$ & 0.50 & 3512 \\
\hline Total score & 7 years & 1.08 & $089,1.32$ & 0.42 & 4777 & 1.13 & $0.89,1.44$ & 0.31 & 3510 & 1.24 & $0.96,1.60$ & 0.09 & 3508 \\
\hline \multicolumn{14}{|l|}{ Cognition } \\
\hline Verbal IQ & 8 years & $1 \cdot 19$ & $1.02,1.39$ & 0.03 & 3997 & 1.08 & $0.89,1.31$ & 0.47 & 2952 & 1.00 & $0.82,1.23$ & 0.98 & 2950 \\
\hline Performance IQ & 8 years & 1.06 & $0.91,1.24$ & 0.43 & 3990 & 0.99 & $0.82,1.20$ & 0.92 & 2945 & 1.00 & $0.82,1.23$ & 0.98 & 2943 \\
\hline Total IQ & 8 years & 1.16 & $1.00,1.35$ & 0.06 & 3978 & 1.02 & $0.84,1.24$ & 0.82 & 2938 & 1.01 & $0.82,1.24$ & 0.93 & 2936 \\
\hline \multicolumn{14}{|l|}{ Reading ability } \\
\hline Words per min & 9 years & $1 \cdot 17$ & $1.00,1.36$ & 0.05 & 3794 & $1 \cdot 14$ & $0.94,1.39$ & 0.18 & 2763 & 1.15 & $0.94,1.42$ & 0.17 & 2761 \\
\hline Accuracy & 9 years & $1 \cdot 16$ & $0.99,1.35$ & 0.07 & 3802 & 1.04 & $0.85,1.28$ & 0.69 & 2767 & 1.03 & $0.83,1.27$ & 0.80 & 2765 \\
\hline Comprehension & 9 years & $1 \cdot 11$ & $0.95,1.30$ & $0 \cdot 18$ & 3802 & 1.02 & $0.83,1.25$ & 0.87 & 2767 & 1.04 & $0.84,1.29$ & 0.73 & 2765 \\
\hline Reading score & 9 years & $1 \cdot 10$ & $0.95,1.27$ & 0.22 & 4125 & 1.06 & $0.88,1.27$ & 0.54 & 3028 & 1.04 & $0.86,1.26$ & 0.69 & 3026 \\
\hline
\end{tabular}

ALSPAC, Avon Longitudinal Study of Parents and Children; IQ, intelligence quotient.

* Suboptimal outcome defined as scores in the bottom quartile for ALSPAC pre-school development assessments, cognition and reading ability. Published cut-offs ${ }^{(17)}$ were used for behaviour: prosocial $(\leq 5 ; 9.8 \%)$, peer problems $(\geq 3 ; 13.5 \%)$, hyperactivity $(\geq 6 ; 18.7 \%)$, emotional symptoms $(\geq 4 ; 12.2 \%)$, conduct problems $(\geq 3 ; 24.3 \%)$ and total score $(\geq 14$; $10.5 \%$ ). Maternal vitamin D status $>50.0 \mathrm{nmol} / /$ was the reference group.

$\dagger$ Model 1 adjusted for gestational week of vitamin D measurement.

‡ Model 2: gestational week of vitamin D measurement plus additional eleven variables: maternal age, maternal BMI, maternal ethnic group, maternal education, maternal social class, parity, tobacco smoking in first trimester, home ownership status, crowding index, child sex, breast-feeding.

$\S$ Model 3: additionally adjusted for oily fish and season of vitamin D measurement.

II Age of child at development test included in all models.

outcomes were correlated with an average $r 0 \cdot 12$ (range -0.03 to 0.69). The impact of these correlations was assessed using simulations. The scores from the 5000 simulated data sets had a mean of 13.52 (SD 2.78). This compared with an expected mean of 13.5 (sD 1.5) if all the outcomes had been independent. The observed results had a score of 6.93 suggesting an empirical twotail $P$ value of $0 \cdot 016$. Sequential analyses by removing those outcomes with the strongest association from the simulated scores suggested that three outcomes (gross and fine-motor development at 30 months and social development at 42 months) had robust associations with the other twenty-four outcomes having associations consistent with chance $(P=0.051)$.

We also explored defining the score based upon the logit transformation, $\ln (P /(1-P))$. Using this definition, the score more closely approximated to a normal distribution. However this did not change the conclusions.

\section{Sensitivity analysis}

When we added the variables, preterm birth and birth weight, to model 3 , the results were fundamentally unchanged (online
Supplementary Table S2), though the effect of maternal vitamin D status on gross-motor development at 18 months and social development at 42 months was no longer statistically significant.

The addition of suboptimal iodine:creatinine ratio in the first trimester to model 3 resulted in considerable sample attrition given the low number of women with iodine measurements ( $n$ 787) (online Supplementary Table S2). Though the effect sizes were larger than previously, the associations between maternal vitamin D and gross-motor development at 18 and 30 months and social development at 42 months were no longer significant, though they remained significant for fine-motor development at 18 (OR 1.50; $95 \%$ CI 1.02, 2.23) and 30 months (OR 1.61; $95 \%$ CI $1 \cdot 06,2 \cdot 46)$.

We explored whether dichotomising women according to different 25(OH)D cut-offs $(25.0$ or $75.0 \mathrm{nmol} / \mathrm{l})$ changed the results (online Supplementary Tables S3 and S4), bearing in mind the lower relative statistical power that results when the cut-off leads to unequal numbers in each group (the $50.0 \mathrm{nmol} / 1$ cut-off was close to the median $25(\mathrm{OH}) \mathrm{D}$ concentration of $54.9 \mathrm{nmol} / \mathrm{l}$ ). When using the $25.0 \mathrm{nmol} / \mathrm{l}$ cut-off, the only outcome associated with vitamin D deficiency in the fully adjusted 
Table 3. Suboptimal outcomes in offspring according to maternal vitamin D status when the $<50.0 \mathrm{nmol} / \mathrm{l}$ group is split into $<25.0$ and $25.0-49.9 \mathrm{nmol} / \mathrm{l}$ and each group is compared with $\geq 50 \cdot 0 \mathrm{nmol} / \mathrm{l}$ (adjusted model 3$)^{*}$

(Odds ratios and $95 \%$ confidence intervals)

\begin{tabular}{|c|c|c|c|c|c|c|c|c|c|}
\hline & \multirow[b]{3}{*}{ Age } & \multicolumn{8}{|c|}{ Maternal vitamin D status (nmol/l) } \\
\hline & & \multicolumn{3}{|c|}{$<25.0$ v. $\geq 50.0$} & \multicolumn{3}{|c|}{$25 \cdot 0-49.9 v . \geq 50.0$} & \multicolumn{2}{|c|}{ Trend } \\
\hline & & OR & $95 \% \mathrm{Cl}$ & $n$ & OR & $95 \% \mathrm{Cl}$ & $n$ & $P$ & $n$ \\
\hline \multicolumn{10}{|c|}{ ALSPAC pre-school development assessments } \\
\hline \multirow[t]{4}{*}{ Gross-motor skills } & 6 months $\dagger$ & $1 \cdot 30$ & $0.90,1.88$ & 169 & 0.92 & $0.77,1.09$ & 1279 & 0.88 & 4380 \\
\hline & 18 months & 1.40 & $1.00,1.96$ & 178 & $1 \cdot 14$ & $0.98,1.33$ & 1270 & 0.02 & 4383 \\
\hline & 30 months & 1.52 & $1 \cdot 07,2 \cdot 17$ & 163 & $1 \cdot 17$ & $0.99,1.37$ & 1213 & 0.008 & 4133 \\
\hline & 42 months & $1 \cdot 24$ & $0.85,1.82$ & 159 & 1.07 & $0.90,1.27$ & 1191 & 0.23 & 4070 \\
\hline \multirow[t]{4}{*}{ Fine-motor skills } & 6 months $\dagger$ & 1.24 & $0.85,1.80$ & 167 & 1.04 & $0.88,1.24$ & 1213 & 0.32 & 4139 \\
\hline & 18 months & 1.03 & $0.72,1.47$ & 177 & $1 \cdot 10$ & $0.94,1.29$ & 1269 & 0.36 & 4381 \\
\hline & 30 months & 1.30 & $0.91,1.88$ & 163 & 1.22 & $1.04,1.44$ & 1214 & 0.01 & 4136 \\
\hline & 42 months & 1.31 & $0.89,1.92$ & 158 & $1 \cdot 14$ & $0.96,1.36$ & 1191 & 0.06 & 4068 \\
\hline \multirow[t]{4}{*}{ Social development } & 6 months $\dagger$ & 1.02 & $0.70,1.50$ & 170 & 1.00 & $0.84,1 \cdot 19$ & 1216 & 0.95 & 4207 \\
\hline & 18 months & 1.28 & $0.88,1.85$ & 177 & $1 \cdot 12$ & $0.95,1.33$ & 1269 & 0.08 & 4381 \\
\hline & 30 months & 0.91 & $0.61,1.36$ & 163 & 1.09 & $0.92,1.30$ & 1212 & 0.66 & 4127 \\
\hline & 42 months & 1.49 & $1 \cdot 02,2 \cdot 18$ & 158 & $1 \cdot 16$ & $0.98,1.38$ & 1190 & 0.02 & 4066 \\
\hline \multirow[t]{2}{*}{ Communication } & 6 months $\dagger$ & 1.41 & $0.93,2.14$ & 167 & 0.94 & $0.77,1 \cdot 16$ & 1237 & 0.59 & 4283 \\
\hline & 18 months & 1.31 & $0.92,1.88$ & 179 & 1.09 & $0.93,1.29$ & 1272 & $0 \cdot 11$ & 4388 \\
\hline \multicolumn{10}{|l|}{ Behaviour } \\
\hline Prosocial & 7 years & 1.11 & $0.59,2.09$ & 124 & 0.99 & $0.75,1.30$ & 1003 & 0.89 & 3511 \\
\hline Peer problems & 7 years & 0.97 & $0.56,1.67$ & 124 & 1.05 & $0.84,1.33$ & 1002 & 0.80 & 3508 \\
\hline Hyperactivity & 7 years & 0.63 & $0.37,1.08$ & 124 & 1.09 & $0.89,1.33$ & 1002 & $0 \cdot 70$ & 3511 \\
\hline Emotional & 7 years & $0 \cdot 80$ & $0.43,1.49$ & 124 & $1 \cdot 25$ & $0.99,1.57$ & 1002 & 0.34 & 3509 \\
\hline Conduct & 7 years & 0.80 & $0.50,1.27$ & 124 & $1 \cdot 10$ & $0.91,1.32$ & 1003 & $0 \cdot 88$ & 3512 \\
\hline Total Score & 7 years & 0.68 & $0.33,1.39$ & 124 & 1.31 & $1.02,1.70$ & 1001 & 0.37 & 3508 \\
\hline \multicolumn{10}{|l|}{ Cognition } \\
\hline Verbal IQ & 8 years & 1.07 & $0.67,1.73$ & 103 & 0.99 & $0.80,1 \cdot 23$ & 839 & 0.90 & 2950 \\
\hline Performance IQ & 8 years & 1.40 & $0.89,2.20$ & 104 & 0.96 & $0.78,1.18$ & 837 & 0.56 & 2943 \\
\hline Total IQ & 8 years & 1.37 & $0.87,2 \cdot 17$ & 103 & 0.97 & $0.78,1.20$ & 834 & 0.54 & 2936 \\
\hline \multicolumn{10}{|l|}{ Reading ability } \\
\hline Words per min & 9 years & $1 \cdot 11$ & $0.68,1.80$ & 101 & $1 \cdot 16$ & $0.94,1.43$ & 797 & 0.23 & 2761 \\
\hline Accuracy & 9 years & 1.14 & $0.70,1.87$ & 101 & 1.02 & $0.81,1.27$ & 799 & 0.69 & 2765 \\
\hline Comprehension & 9 years & 1.01 & $0.61,1.66$ & 101 & 1.04 & $0.84,1.30$ & 799 & 0.78 & 2765 \\
\hline Reading score & 9 years & 0.91 & $0.57,1.45$ & 108 & 1.06 & $0.87,1.29$ & 872 & 0.88 & 3026 \\
\hline
\end{tabular}

ALSPAC, Avon Longitudinal Study of Parents and Children; IQ, intelligence quotient.

* Suboptimal outcome defined as scores in the bottom quartile for ALSPAC pre-school development assessments, cognition and reading ability. Published cut-offs ${ }^{(17)}$ were used for behaviour: prosocial $(\leq 5 ; 9.8 \%)$, peer problems ( $\geq 3 ; 13.5 \%)$, hyperactivity ( $\geq 6 ; 18.7 \%)$, emotional symptoms $(\geq 4 ; 12.2 \%)$, conduct problems $(\geq 3 ; 24.3 \%)$ and total score $(\geq 14 ; 10.5 \%)$. Maternal vitamin $\mathrm{D}$ status $\geq 50.0 \mathrm{nmol} / \mathrm{l}$ was the reference group.

$\dagger$ Age of child at development test included in all models.

model was gross-motor development at 30 months (OR 1.43; $95 \%$ CI 1.01, 2.02); results approached statistical significance for other outcomes (e.g. social development at 42 months, OR 1.40; $95 \%$ CI 0.97, 2.02; online Supplementary Table S3). Using a cutoff of $75.0 \mathrm{nmol} / 1$ to define deficiency resulted in null associations with the ALSPAC pre-school development assessments, behaviour and cognitive tests, but was associated with higher odds of suboptimal reading accuracy at 9 years (OR 1.26; $95 \%$ CI 1.01, 1.57); however, this may be a chance finding as reading accuracy was not associated with vitamin D in any other analyses (Tables 2-4 and online Supplementary Tables S2 and S3).

\section{Discussion}

After adjustment for potential confounders, children born to vitamin D-deficient mothers (serum $25(\mathrm{OH}) \mathrm{D}$ of $<50 \cdot 0 \mathrm{nmol} / \mathrm{l}$ ) were more likely to have suboptimal gross-motor skills at 30 months, suboptimal fine-motor skills at 30 months and suboptimal social development scores at 42 months than were children born to sufficient mothers $(\geq 50.0 \mathrm{nmol} / \mathrm{l})$. Although the effect sizes were relatively small, we consider that the findings were biologically meaningful. Interestingly, no associations were found between maternal vitamin D status and other outcomes (IQ, reading ability).

These results suggest that the vitamin D content of seafood might explain some of the beneficial effects of maternal seafood consumption seen previously in ALSPAC, at least for fine-motor skills at 30 months and social skills at 42 months $^{(1)}$. The classification of maternal seafood consumption by Hibbeln et al. ${ }^{(1)}$ included white fish and shellfish which are not good sources of dietary vitamin $\mathrm{D}$, therefore, we would not expect vitamin $\mathrm{D}$ intake to account totally for their findings. Furthermore, our results cannot explain previous associations found in ALSPAC between maternal seafood consumption and $\mathrm{IQ}^{(1)}$ or between maternal iodine status and IQ and reading ability ${ }^{(22)}$.

Our findings on fine- and gross-motor skills support previous non-ALSPAC-based research that found a positive association between maternal vitamin D status and infant psychomotor development ${ }^{(11)}$. Although we did not specifically measure scholastic achievement, the lack of an association between 
Table 4. Suboptimal outcomes in offspring by maternal vitamin $D$ status $(<50.0 \mathrm{v} . \geq 50.0 \mathrm{nmol} / \mathrm{l})$ according to whether maternal vitamin $\mathrm{D}$ was measured in the first or second half of gestation (adjusted model 3$)^{\star}$ (Odds ratios and $95 \%$ confidence intervals)

\begin{tabular}{|c|c|c|c|c|c|c|c|c|c|c|}
\hline & \multirow[b]{2}{*}{ Age } & \multicolumn{4}{|c|}{ First half of gestation ( $\leq 22$ weeks) } & \multicolumn{4}{|c|}{ Second half of gestation (>22 weeks) } & \multirow[b]{2}{*}{$P_{\text {for interaction }} t$} \\
\hline & & OR & $95 \% \mathrm{Cl}$ & $P$ & $n$ & OR & $95 \% \mathrm{Cl}$ & $P$ & $n$ & \\
\hline \multicolumn{11}{|c|}{ ALSPAC pre-school development assessments } \\
\hline \multirow[t]{4}{*}{ Gross-motor skills } & 6 months $\ddagger$ & 0.92 & $0.70,1.22$ & 0.56 & 1500 & 0.98 & $0.79,1.21$ & 0.84 & 2880 & 0.21 \\
\hline & 18 months & 0.97 & $0.76,1.23$ & 0.78 & 1522 & $1 \cdot 31$ & $1.08,1.58$ & 0.005 & 2861 & $0 \cdot 13$ \\
\hline & 30 months & 1.07 & $0.84,1.38$ & 0.58 & 1435 & 1.28 & $1.05,1.57$ & 0.02 & 2698 & 0.79 \\
\hline & 42 months & 1.03 & $0.79,1.34$ & 0.85 & 1422 & $1 \cdot 10$ & $0.89,1.36$ & 0.37 & 2648 & 0.72 \\
\hline \multirow[t]{4}{*}{ Fine-motor skills } & 6 months $\ddagger$ & 1.09 & $0.83,1.44$ & 0.52 & 1436 & 1.03 & $0.83,1.27$ & 0.80 & 2703 & 0.25 \\
\hline & 18 months & 1.05 & $0.82,1.36$ & 0.69 & 1522 & $1 \cdot 10$ & $0.90,1.33$ & 0.35 & 2859 & 0.46 \\
\hline & 30 months & 0.99 & $0.76,1.29$ & 0.95 & 1436 & 1.37 & $1.12,1.67$ & 0.002 & 2700 & 0.05 \\
\hline & 42 months & 1.03 & $0.78,1.37$ & 0.83 & 1420 & 1.24 & $1.00,1.53$ & 0.05 & 2648 & 0.37 \\
\hline \multirow[t]{4}{*}{ Social development } & 6 months $\ddagger$ & 0.88 & $0.66,1.16$ & 0.37 & 1453 & $1 \cdot 11$ & $0.90,1.38$ & 0.32 & 2754 & 0.90 \\
\hline & 18 months & 1.23 & $0.95,1.60$ & 0.12 & 1522 & 1.07 & $0.87,1.32$ & 0.51 & 2859 & $0 \cdot 11$ \\
\hline & 30 months & 0.96 & $0.74,1.26$ & 0.79 & 1431 & 1.13 & $0.91,1.40$ & 0.28 & 2696 & 0.36 \\
\hline & 42 months & 1.07 & $0.82,1.41$ & 0.62 & 1420 & $1 \cdot 28$ & $1.03,1.58$ & 0.02 & 2646 & 0.26 \\
\hline \multirow[t]{2}{*}{ Communication } & 6 months $\ddagger$ & 0.90 & $0.65,1.23$ & 0.50 & 1468 & 1.04 & $0.81,1.34$ & 0.75 & 2815 & 0.37 \\
\hline & 18 months & 1.27 & $0.98,1.65$ & 0.07 & 1524 & 1.04 & $0.85,1.28$ & 0.71 & 2864 & $0 \cdot 17$ \\
\hline \multicolumn{11}{|l|}{ Behaviour } \\
\hline Prosocial§ & 7 years & 0.75 & $0.48,1.17$ & 0.21 & 1216 & $1 \cdot 15$ & $0.83,1.61$ & 0.40 & 2301 & $0 \cdot 10$ \\
\hline Peer problems & 7 years & $1 \cdot 14$ & $0.78,1.66$ & 0.49 & 1210 & 0.97 & $0.73,1.30$ & 0.86 & 2298 & 0.55 \\
\hline Hyperactivity & 7 years & 0.95 & $0.68,1.33$ & 0.75 & 1213 & $1 \cdot 10$ & $0.86,1.41$ & 0.46 & 2298 & 0.31 \\
\hline Emotional§ & 7 years & 1.25 & $0.87,1.80$ & 0.23 & 1214 & $1 \cdot 17$ & $0.87,1.58$ & 0.29 & 2301 & 0.71 \\
\hline Conduct & 7 years & $1 \cdot 13$ & $0.84,1.52$ & 0.42 & 1212 & 1.04 & $0.82,1.31$ & 0.74 & 2300 & 0.76 \\
\hline Total score§ & 7 years & 1.20 & $0.79,1.82$ & 0.40 & 1214 & 1.24 & $0.90,1.71$ & 0.18 & 2300 & 0.79 \\
\hline \multicolumn{11}{|l|}{ Cognition } \\
\hline Verbal IQ & 8 years & 1.09 & $0.77,1.55$ & 0.64 & 1025 & 0.93 & $0.72,1.21$ & 0.60 & 1925 & 0.20 \\
\hline Performance IQ & 8 years & 1.15 & $0.83,1.59$ & 0.42 & 1017 & 0.89 & $0.68,1.16$ & 0.38 & 1926 & 0.03 \\
\hline Total IQ & 8 years & $1 \cdot 18$ & $0.84,1.66$ & 0.33 & 1015 & 0.90 & $0.69,1.17$ & 0.43 & 1921 & 0.13 \\
\hline \multicolumn{11}{|l|}{ Reading ability } \\
\hline Words per min & 9 years & 1.41 & $1.00,1.97$ & 0.05 & 936 & 1.00 & $0.77,1.31$ & 0.98 & 1825 & 0.20 \\
\hline Accuracy & 9 years & 1.31 & $0.92,1.87$ & 0.13 & 938 & 0.87 & $0.66,1.14$ & 0.32 & 1827 & 0.06 \\
\hline Comprehension & 9 years & 1.09 & $0.77,1.55$ & 0.62 & 938 & 0.98 & $0.75,1.29$ & 0.89 & 1827 & 0.31 \\
\hline Reading score & 9 years & 1.30 & $0.94,1.78$ & 0.11 & 1060 & 0.91 & $0.71,1.16$ & 0.44 & 1966 & 0.20 \\
\hline
\end{tabular}

ALSPAC, Avon Longitudinal Study of Parents and Children; IQ, intelligence quotient.

* Suboptimal outcome defined as scores in the bottom quartile for ALSPAC pre-school development assessments, cognition and reading ability. Published cut-offs ${ }^{(17)}$ were used for behaviour: prosocial $(\leq 5 ; 9.8 \%)$, peer problems ( $\geq 3 ; 13.5 \%$ ), hyperactivity ( $\geq 6 ; 18.7 \%)$, emotional symptoms $(\geq 4 ; 12.2 \%)$, conduct problems $(\geq 3 ; 24.3 \%)$ and total score $(\geq 14 ; 10.5 \%$ ). Maternal vitamin $D$ status $\geq 50.0 \mathrm{nmol} / \mathrm{l}$ was the reference group and model 3 was used (without gestational week of vitamin $D$ assessment as this was used to split analyses).

$\dagger$ Interaction between vitamin D (deficient/sufficient) and gestational week of sample (continuous variable).

$\ddagger$ Age of child at development test included in all models.

$\S$ Ethnicity removed as model would not converge.

maternal vitamin D status and either reading ability or IQ in our study reinforces the findings of a previous study that found no relationship between maternal $25(\mathrm{OH}) \mathrm{D}$ status and offspring scholastic achievement ${ }^{(10)}$. Although a US study found a relationship between maternal vitamin $\mathrm{D}$ status and offspring IQ, the effect estimates were very small and there was very little indication of an association between maternal blood $25(\mathrm{OH}) \mathrm{D}$ and cognitive development, achievement or behaviour between 8 months and 7 years of age ${ }^{(12)}$.

Our findings suggest that some specific aspects of early neurocognitive development may be suboptimal if maternal prenatal vitamin $D$ is deficient (i.e. serum $25(\mathrm{OH}) \mathrm{D}$ of $<50.0 \mathrm{nmol} / \mathrm{l}$ ) in pregnancy. The biological mechanism underpinning this association in humans is not fully understood, but the ubiquitous presence of the vitamin D receptor (VDR) and the hydroxylase enzymes controlling vitamin D metabolism in a wide variety of areas of the human brain ${ }^{(6)}$, as well as neurological developmental mechanisms previously identified in studies of vitamin D deficiency in pregnant rats may be relevant ${ }^{(7,9,28,29)}$. These include enlarged brain ventricles, thinner neocortex ${ }^{(29)}$ and more mitotic cells in the brain ${ }^{(29)}$, suggesting a less differentiated phenotype ${ }^{(28)}$. The active form of vitamin $\mathrm{D}\left(1,25(\mathrm{OH})_{2} \mathrm{D}\right)$, may also affect the development of the brain by influencing the production of cytokines $^{(30)}$, affecting neurotransmission ${ }^{(31)}$ and synaptic plasticity ${ }^{(31)}$ which is likely to affect learning processes ${ }^{(32)}$ and therefore neurocognitive development. $1,25(\mathrm{OH})_{2} \mathrm{D}$ likely affects dopamine activity in the brain owing to the presence of the VDR in brain areas responsive to dopamine ${ }^{(33)}$. Ventral midbrain dopaminergic neurones are known to play a key role in the modulation of motor behaviour ${ }^{(34)}$. It is therefore feasible that $1,25(\mathrm{OH})_{2} \mathrm{D}$ may affect motor development via its effects on the dopaminergic system. Other potential mechanisms may relate to an association between maternal $25(\mathrm{OH}) \mathrm{D}$ status and fetal growth retardation (e.g. reduced fetal head size) which is associated with later developmental disabilities ${ }^{(35)}$. A recent study in the Generation R cohort in the Netherlands found an association between lower maternal 25(OH)D status at 20 weeks gestation 
and smaller fetal-head circumference in the third trimester ${ }^{(36)}$, suggesting that poorer maternal $25(\mathrm{OH}) \mathrm{D}$ status may predispose children to developmental delay via effects on intrauterine growth restriction.

When we assessed the impact of gestational age on our results for outcomes that were significantly associated with vitamin $\mathrm{D}$ in the main analyses, we found that the effect sizes were generally greater when vitamin $\mathrm{D}$ was measured in the second half ( $>22$ weeks) than in the first half ( $\leq 22$ weeks) of pregnancy. There is a small amount of evidence in rats that reintroduction of vitamin $\mathrm{D}$ after birth, but before end of weaning, can rescue normal brain development ${ }^{(28)}$; that time period corresponds to the third trimester in humans, suggesting a potential crucial window for vitamin $\mathrm{D}$ in brain development. However, all interpretations in our analysis of gestational timing need to be interpreted in light of the fact that we only had one measurement of maternal vitamin D status for each woman and so we cannot draw clear conclusions on the effects of gestational timing of vitamin D deficiency. Furthermore, we cannot be sure that our observed effects are confined to the gestational week that the $25(\mathrm{OH}) \mathrm{D}$ measurement was made, as some individuals may have persistent pattern of vitamin D status that extends into later pregnancy or infancy.

When the women were split into three groups (serum $25(\mathrm{OH}) \mathrm{D}$ of $<25 \cdot 0,25 \cdot 0-49 \cdot 9$ and $\geq 50 \cdot 0 \mathrm{nmol} / \mathrm{l})$, adverse outcomes were present in the offspring of mothers with insufficient status (serum $25(\mathrm{OH}) \mathrm{D}<50 \mathrm{nmol} / \mathrm{l}$ ) as well as those with severe deficiency (serum $25(\mathrm{OH}) \mathrm{D}<25 \mathrm{nmol} / \mathrm{l})$. However, there was a trend to larger effect sizes in the more deficient $<25.0 \mathrm{nmol} / 1$ group than in the $25.0-49.9 \mathrm{nmol} / 1$ group; the relatively small sample size in the $<25.0 \mathrm{nmol} / 1$ group explains the wider CI seen for this cut-off. The outcomes that were significantly associated with vitamin $\mathrm{D}$ when women were dichotomised on the basis of a cut-off of $50.0 \mathrm{nmol} / 1$ were not significant when the cut-off was increased to $75.0 \mathrm{nmol} / \mathrm{l}$. These findings support a vitamin D status cut-off for optimal child outcomes closer to $50.0 \mathrm{nmol} / 1$ than to $75.0 \mathrm{nmol} / 1$.

As the women in the ALSPAC study were recruited over 20 years ago, we compared their vitamin D status with more recent measurements in UK women to assess the current relevance of our findings. As $25(\mathrm{OH}) \mathrm{D}$ status does not differ between pregnant and non-pregnant women ${ }^{(15)}$ we looked at nationally representative data in UK women from the recent National Diet and Nutrition Survey (NDNS). In the latest report (sampling 2008/2009-2011/2012), 21.7\% of women of 19-64 years had a plasma $25(\mathrm{OH}) \mathrm{D}$ concentration below $25 \mathrm{nmol} / \mathrm{l}^{(37)}$, a higher percentage than the $4.4 \%$ of women in ALSPAC. Other studies ${ }^{(38,39)}$, including those in pregnancy, suggest that many UK women are vitamin $\mathrm{D}$ deficient. Currently, the UK National Institute for Health and Care Excellence recommends that pregnant women should take a supplement of $10 \mu \mathrm{g}$ of vitamin $\mathrm{D}$ per $\mathrm{d}^{(40)}$. However use of vitamin D supplements in pregnancy is low, with a recent survey (2005-2009) finding that only $1.4 \%$ of UK pregnant women had taken a vitamin D supplement ${ }^{(41)}$. Our findings give further evidence that public-health campaigns should address the vitamin D status of UK pregnant women, and encourage compliance with the $10 \mu \mathrm{g} / \mathrm{d}$ recommendation ${ }^{(40)}$.

\section{Strengths and limitations}

Although our study has several strengths, including the large sample size, there are also limitations. First each woman had only one measure of maternal vitamin D status in pregnancy which may not have reflected status over the whole of pregnancy. In addition, the range of vitamin D status in the ALSPAC women was limited, with approximately one-third (34.6\%) having a $25(\mathrm{OH}) \mathrm{D}$ concentration less than $50.0 \mathrm{nmol} / \mathrm{l}$ and only a small proportion having a $25(\mathrm{OH}) \mathrm{D}$ concentration $<25.0 \mathrm{nmol} / 1$ ( $4.4 \%$ ). Moreover, ALSPAC only has a relatively small number of women from ethnic-minority backgrounds (just $2 \%$ of this study sample), who are known to be at particular risk of having low $25(\mathrm{OH}) \mathrm{D}$ concentrations ${ }^{(42)}$, suggesting that the results may differ in populations with a larger number of ethnic-minority individuals. Finally, we were not able to control for the association between infant vitamin D status and neurocognitive function as we had no measures of vitamin D status in infancy. Infant vitamin D status may partly explain some of the association seen in this paper between maternal vitamin D status and infant neurodevelopment.

In conclusion, we found that maternal vitamin $\mathrm{D}$ status in pregnancy was associated with a number of adverse neurocognitive developmental variables in early childhood, albeit with a small, but nonetheless important, effect size. There is a need for replication of this work in other settings to confirm these results, but the public-health implications of these findings are nevertheless potentially important. Further study is now urgently required, particularly in population groups that are more severely vitamin D deficient such as dark-skinned ethnicminority women ${ }^{(37)}$ whose children may show a wider range and greater severity of suboptimal neurocognitive outcomes.

\section{Acknowledgements}

The authors are extremely grateful to all the families who took part in this study, the midwives for their help in recruiting them, and the whole ALSPAC team, which includes interviewers, computer and laboratory technicians, clerical workers, research scientists, volunteers, managers, receptionists and nurses.

This work was supported by the following funding bodies: The UK Medical Research Council and Wellcome Trust (grant no. 102215/2/13/2) and the University of Bristol currently provide core support for ALSPAC. The work was also supported by a UK Medical Research Council Population Health Scientist Fellowship (S. C. B., grant no. MR/K02132X/1). The UK Medical Research Council provided funds to ALSPAC for completion of the 25(OH)D assays used in this paper (grant no. G0701603).

A. L. D., S. C. B. and J. G. designed the current research project. S. C. B. and A. L. D. conducted the statistical analyses with statistical advice from C. D. S., M. P. R. and J. G. M. P. R., J. G., C. D. S. and S. A. L.-N. revised the paper and made suggestions on the content. A. L. D. and S. C. B. wrote the paper. S. C. B. has primary responsibility for final content.

S. A. L.-N. is the Research Director of D3Tex Ltd which holds the UK Patent (Gulf Cooperation Council Patent pending) on the use of UVB transparent material for vitamin D deficiency prevention. All other authors declare that there are no conflicts of interest. 


\section{Supplementary material}

For supplementary material/s referred to in this article, please visit https://doi.org/10.1017/S0007114517001398

\section{References}

1. Hibbeln JR, Davis JM, Steer C, et al. (2007) Maternal seafood consumption in pregnancy and neurodevelopmental outcomes in childhood (ALSPAC study): an observational cohort study. Lancet 369, 578-585.

2. Daniels JL, Longnecker MP, Rowland AS, et al. (2004) Fish intake during pregnancy and early cognitive development of offspring. Epidemiology 15, 394-402.

3. Gale CR, Robinson SM, Godfrey KM, et al. (2008) Oily fish intake during pregnancy - association with lower hyperactivity but not with higher full-scale IQ in offspring. J Child Psychol Psychiatry 49, 1061-1068.

4. Julvez J, Mendez M, Fernandez-Barres S, et al. (2016) Maternal consumption of seafood in pregnancy and child neuropsychological development: a longitudinal study based on a population with high consumption levels. Am J Epidemiol 183, 169-182.

5. Brock K, Huang WY, Fraser DR, et al. (2010) Low vitamin D status is associated with physical inactivity, obesity and low vitamin D intake in a large US sample of healthy middleaged men and women. J Steroid Biochem Mol Biol 121, 462-466.

6. Eyles DW, Smith S, Kinobe R, et al. (2005) Distribution of the vitamin $\mathrm{D}$ receptor and 1 alpha-hydroxylase in human brain. J Chem Neuroanat 29, 21-30.

7. Eyles DW, Feron F, Cui X, et al. (2009) Developmental vitamin $\mathrm{D}$ deficiency causes abnormal brain development. Psychoneuroendocrinology 34, Suppl. 1, S247-S257.

8. O'Loan J, Eyles DW, Kesby J, et al. (2007) Vitamin D deficiency during various stages of pregnancy in the rat; its impact on development and behaviour in adult offspring. Psychoneuroendocrinology 32, 227-234.

9. Feron F, Burne TH, Brown J, et al. (2005) Developmental vitamin $\mathrm{D}_{3}$ deficiency alters the adult rat brain. Brain Res Bull 65, 141-148

10. Strom M, Halldorsson TI, Hansen S, et al. (2014) Vitamin D measured in maternal serum and offspring neurodevelopmental outcomes: a prospective study with long-term follow-up. Ann Nutr Metab 64, 254-261.

11. Morales E, Guxens M, Llop S, et al. (2012) Circulating 25-hydroxyvitamin $\mathrm{D}_{3}$ in pregnancy and infant neuropsychological development. Pediatrics 130, e913-e920.

12. Keim SA, Bodnar LM \& Klebanoff MA (2014) Maternal and cord blood 25(OH)-vitamin D concentrations in relation to child development and behaviour. Paediatr Perinat Epidemiol 28, 434-444

13. Whitehouse AJ, Holt BJ, Serralha M, et al. (2012) Maternal serum vitamin D levels during pregnancy and offspring neurocognitive development. Pediatrics 129, 485-493.

14. Hanieh S, Ha TT, Simpson JA, et al. (2014) Maternal vitamin D status and infant outcomes in rural Vietnam: a prospective cohort study. PLOS ONE 9, e99005.

15. Scientific Advisory Committee for Nutrition (2016) Vitamin D and health, https://www.gov.uk/government/publications/ sacn-vitamin-d-and-health-report (accessed March 2017).

16. Boyd A, Golding J, Macleod J, et al. (2013) Cohort profile: the 'children of the 90s' - the index offspring of the Avon Longitudinal Study of Parents and Children. Int J Epidemiol 42, 111-127.

17. Goodman R (1997) The Strengths and Difficulties Questionnaire: a research note. J Child Psychol Psychiatry 38, 581-586.
18. Neale M (1997) Neale Analysis of Reading Ability - Revised. Windsor: NFER-Nelson.

19. Seamans KM \& Cashman KD (2009) Existing and potentially novel functional markers of vitamin D status: a systematic review. Am J Clin Nutr 89, 1997s-2008s.

20. Lawlor DA, Wills AK, Fraser A, et al. (2013) Association of maternal vitamin D status during pregnancy with bonemineral content in offspring: a prospective cohort study. Lancet 381, 2176-2183.

21. Sullivan S, Wills A, Lawlor D, et al. (2013) Prenatal vitamin D status and risk of psychotic experiences at age 18years-a longitudinal birth cohort. Schizophr Res 148, 87-92.

22. Bath SC, Steer CD, Golding J, et al. (2013) Effect of inadequate iodine status in UK pregnant women on cognitive outcomes in their children: results from the Avon Longitudinal Study of Parents and Children (ALSPAC). Lancet 382, 331-337.

23. Tolppanen AM, Fraser A, Fraser WD, et al. (2012) Risk factors for variation in 25-hydroxyvitamin $\mathrm{D}(3)$ and $\mathrm{D}(2)$ concentrations and vitamin D deficiency in children. J Clin Endocrinol Metab 97, 1202-1210.

24. Schoon I, Jones E, Cheng H, et al. (2012) Family hardship, family instability, and cognitive development. J Epidemiol Community Health 66, 716-722.

25. Samuel L \& Borrell LN (2013) The effect of body mass index on optimal vitamin D status in US adults: the National Health and Nutrition Examination Survey 2001-2006. Ann Epidemiol 23, 409-414.

26. Kuoppala T, Tuimala R, Parviainen M, et al. (1986) Serum levels of vitamin $\mathrm{D}$ metabolites, calcium, phosphorus, magnesium and alkaline phosphatase in Finnish women throughout pregnancy and in cord serum at delivery. Hum Nutr Clin Nutr 40, 287-293.

27. Heaney RP (2013) Health is better at serum 25(OH)D above 30 ng/mL. J Steroid Biochem Mol Biol 136, 224-228.

28. Cui X, Gooch H, Groves NJ, et al. (2015) Vitamin D and the brain: key questions for future research. J Steroid Biochem Mol Biol 148, 305-309.

29. Eyles D, Brown J, Mackay-Sim A, et al. (2003) Vitamin $\mathrm{D}_{3}$ and brain development. Neuroscience 118, 641-653.

30. van Etten E \& Mathieu C (2005) Immunoregulation by 1,25-dihydroxyvitamin $\mathrm{D}_{3}$ : basic concepts. J Steroid Biochem Mol Biol 97, 93-101.

31. Almeras L, Eyles D, Benech P, et al. (2007) Developmental vitamin $\mathrm{D}$ deficiency alters brain protein expression in the adult rat: implications for neuropsychiatric disorders. Proteomics 7, 769-780.

32. Becker A, Eyles DW, McGrath JJ, et al. (2005) Transient prenatal vitamin D deficiency is associated with subtle alterations in learning and memory functions in adult rats. Behav Brain Res 161, 306-312.

33. Kesby JP, Eyles DW, Burne TH, et al. (2011) The effects of vitamin D on brain development and adult brain function. $\mathrm{Mol}$ Cell Endocrinol 347, 121-127.

34. Van den Heuvel DMA \& Pasterkamp RJ (2008) Getting connected in the dopamine system. Prog Neurobiol 85, 75-93.

35. Watemberg N, Silver S, Harel S, et al. (2002) Significance of microcephaly among children with developmental disabilities. J Child Neurol 17, 117-122.

36. Miliku K, Vinkhuyzen A, Blanken LM, et al. (2016) Maternal vitamin $\mathrm{D}$ concentrations during pregnancy, fetal growth patterns, and risks of adverse birth outcomes. Am J Clin Nutr 103, 1514-1522.

37. Bates B, Lennox A, Prentice A, et al. (2014) National Diet and Nutrition Survey: Results from Years 1, 2, 3 and 4 (Combined) of the Rolling Programme (2008/2009-2011/2012). London: Public Health England. 
38. Macdonald HM, Mavroeidi A, Fraser WD, et al. (2011) Sunlight and dietary contributions to the seasonal vitamin $\mathrm{D}$ status of cohorts of healthy postmenopausal women living at northerly latitudes: a major cause for concern? Osteoporosis Int 22, 2461-2472.

39. Javaid MK, Crozier SR, Harvey NC, et al. (2006) Maternal vitamin D status during pregnancy and childhood bone mass at age 9 years: a longitudinal study. Lancet 367, 36-43.

40. National Institute for Health and Care Excellence (2014) Vitamin D: increasing supplement use in at-risk groups
(PH56). http://www.nice.org.uk/guidance/ph56 (accessed November 2015).

41. Oliver EM, Grimshaw KEC, Schoemaker AA, et al. (2014) Dietary habits and supplement use in relation to national pregnancy recommendations: data from the EuroPrevall birth cohort. Matern Child Health $J \mathbf{1 8}$, $2408-2425$.

42. Cashman KD, Dowling KG, Skrabakova Z, et al. (2016) Vitamin D deficiency in Europe: pandemic? Am J Clin Nutr 103, 1033-1044. 